UCRL-JC-130975

PREPRINT

\title{
Main Amplifier Power Conditioning for the National Ignition Facility
}

\author{
M. Newton \\ M. Wilson
}

This paper was prepared for submittal to the 1998 American Nuclear Society Annual Meeting

Nashville, TN

June 7-11, 1998

June 8, 1998

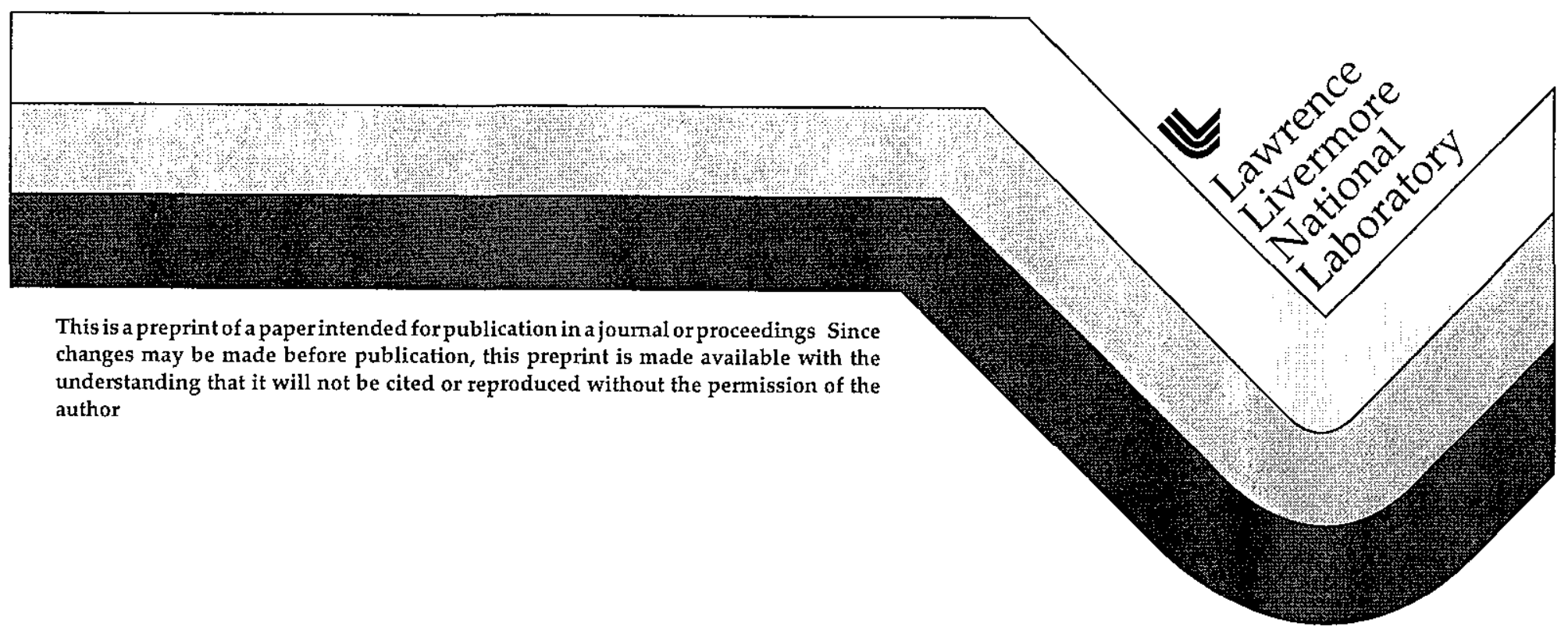




\section{DISCLAIMER}

This document was prepared as an account of work sponsored by an agency of the United States Government. Neither the United States Government nor the University of California nor any of their employees, makes any warranty, express or implied, or assumes any legal liability or responsibility for the accuracy, completeness, or usefulness of any information, apparatus, product, or process

disclosed, or represents that its use would not infringe privately owned rights. Reference herein to any specific commercial product, process, or service by trade name, trademark, manufacturer, or otherwise, does not necessarily constitute or imply its endorsement, recommendation, or favoring by the United States Government or the University of California. The views and opinions of authors expressed herein do not necessarily state or reflect those of the United States Government or the University of California, and shall not be used for advertising or product endorsement purposes. 


\section{MAIN AMPLIFIER POWER CONDITIONING FOR THE NATIONAL IGNITION FACHITY}

Mark Newton

Lawrence Livermore National Laboratory

PO Box 808

Livermore, CA 94550

(925) 422-1861

\begin{abstract}
The National Ignition Facility (NIF), being built at Lawrence Livermore National Laboratory (LLNL) will utilize a $18 \mathrm{MJ}$ glass laser to study inertial confinement fusion This laser will be driven by a power conditioning system which must simultaneously deliver over $260 \mathrm{MJ}$ of electrical energy to the nearly 7700 flashlamps The power conditioning system is divided into independent modules that store, shape and deliver pulses of energy to the flashlamps

The NIF power conditioning system which is being designed and built by Sandia National Laboratory (SNL) in collaboration with LLNL and industrial partners, is a different architecture from any laser power conditioning system previously built at LLNL This particular design architecture was chosen as the most costeffective way to reliably deliver the large amount of energy needed for NIF

This paper will describe the development and design of the NIF power conditioning system It will discuss the design objectives as well as the key design issues and technical hurdles that are being addressed in an ongoing component development and system validation program being supported by both SNL and LLNL
\end{abstract}

\section{INTRODUCTION}

The National Ignition Facility (NIF) is presently being built at Lawrence Livermore National Laboratory (LLNL) for the US Department of Energy to study inertial confinement fusion (ICF) The NIF is being built in partnership with Los Alamos National Laboratory (LANL), Sandia National Laboratory (SNL), and the University of Rochester's
Mike Wilson

Sandia National Laboratory

P O Box 5800

Albuquerque, NM 87185

(505) $844-9598$

Laboratory for Laser Energetics and is scheduled for completion in late 2003

One of the primary components of the NIF is a large glass laser system that will deliver a total of $18 \mathrm{MJ}$ of optical energy to a fusion target The power to drive this 192-beam laser system is supplied by the Amplifier Power Conditioning System (APCS) The APES generates and delivers precise pulses of electrical energy to each of the 7680 flashlamps in the NIF laser This paper will describe the requirements, design and predicted performance of the APCS

\section{SYSTEM DESCROPTION}

The NIF laser is housed in two large laser bays each of which contain two laser "clusters" Each laser cluster is composed of six bundles of eight laser beams This configuration is illustrated in Figure 1

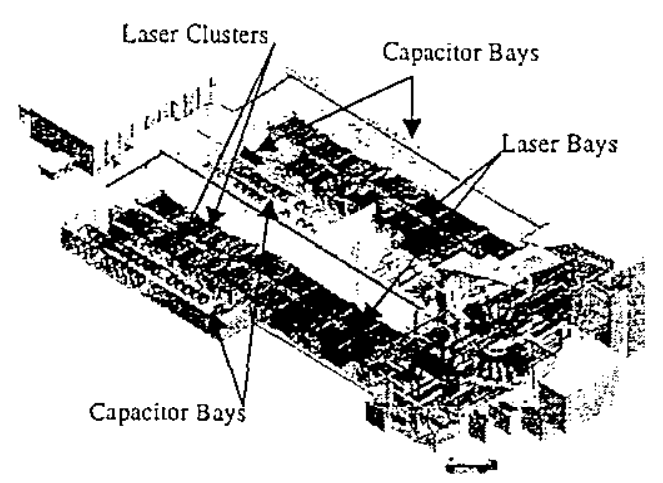

Figure 1. Layout of the NIF facility.

The power conditioning equipment is located in capacitor bays adjacent to each laser cluster Each capacitor bay houses 48 independent, power conditioning modules each having a maximum capacity for energy storage of nearly $2 \mathrm{MJ}$ Each module drives a total of 40 
flashlamps which are configured as 20 circuits, each circuit having two lamps in series

Typical voltage and current waveforms for energizing the NIF flashlamps are shown in Figure 2 and Figure 3 This pulse format includes features for triggering, pre-ionization and the main discharge as denoted in the figures

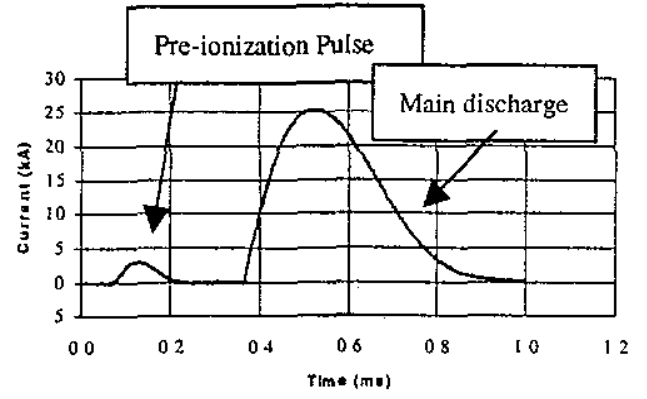

Figure 2. Flashlamp drive current

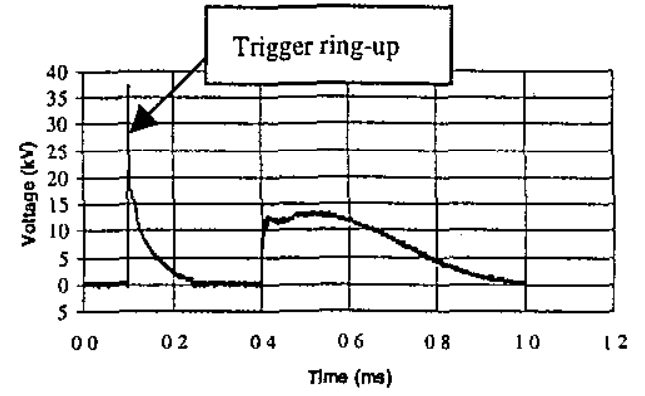

Figure 3. Voltage across flashlamp.

The flashlamp triggering mechanism consists of an initial breakdown from one electrode to the inside wall of the flashlamp This initial breakdown is followed by a streamer that propagates along the wall toward the other electrode $^{l}$ Tests have shown that the reliable triggering of a series pair of the NIF flashlamps can be achieved with a $40-50 \mathrm{kV}$ short voltage ring-up that lasts for 5-10 microseconds

The purpose of pre-ionization is to prepare or condition the flashlamp for the main discharge It has been shown that pre-ionization strongly effects the radiant efficiency of the flashlamps ${ }^{2}$ The required pre-ionization pulse energy is only a small fraction of the energy supplied during the main discharge

In a system the size of NIF it is important to be able to detect the failure of flashlamps The purpose of the "lampcheck" is to verify the integrity of the flashlamps in the system before the laser is fired This is to prevent discharge of the banks into broken or faulty lamps, which may cause excessive damage inside the laser amplifier The lampcheck pulse is identical to the pre-ionization pulse and is provided by the same circuit The only difference is that it is fired independent of the main discharge pulse

\section{SYSTEM REQUIREMENTS}

The design of the PCS is driven by subsystem design requirements that are derived from the overall performance and operational goals of the laser system These requirements define the performance, lifetime, reliability and maintainability that must be achieved by the PCS This paper will focus primarily on the performance and lifetime requirements

\section{A Performance Specifications}

One of the important measures of the NIF laser amplifier performance is the gain coefficient of the amplifier The gain coefficient is a measure of the change in light intensity vs the path length of the light through the laser glass The gain coefficient is dependent not only on the laser glass but also on the temporal characteristics of the light pulses generated by the flashlamps The desired temporal characteristics of the flashlamp light translate directly into requirements on the shape, amplitude and timing of the pulses delivered by the power conditioning system For this reason, the primary requirement for the APCS was written in terms of amplifier gain coefficient

A computer model, GainCalc v1 0 , has been developed to calculate the gain coefficient of the NIF amplifier for a given electrical drive input ${ }^{3}$ This code is used to verify that the output waveforms of the APCS meet the gain coefficient requirement A summary of the other requirements on the main discharge pulse are also shown in Table 1

The pre-ionization pulse requirements are shown in Table 2 The performance of the preionization system has less impact on the performance of the amplifier than the main discharge The most critical parameters are the total energy delivered and the pulse duration 


\begin{tabular}{|l|l|}
\hline \multicolumn{1}{|c|}{$\begin{array}{c}\text { Main Pulse } \\
\text { Characteristics }\end{array}$} & \multicolumn{1}{c|}{ Requirement } \\
\hline $\begin{array}{l}\text { Average Gain } \\
\text { Coefficient }\end{array}$ & $>50 \% / \mathrm{cm}$ \\
\hline Discharge Pulse Shape & $\begin{array}{l}\text { Duration of power } \\
\text { pulse delivered to } \\
\text { flashlamps shall be 360 } \\
\mu \text { s } \pm 10 \%\end{array}$ \\
\hline Repeatability & $\begin{array}{l}\text { Total delivered energy } \\
\text { repeatable to } \pm 1 \% \text { shot } \\
\text { to shot }\end{array}$ \\
\hline Resolution & $\begin{array}{l}\text { Delivered energy } \\
\text { settable to } \pm 05 \%\end{array}$ \\
\hline Uniformity & $\begin{array}{l}\text { Energy variation }< \pm \\
3 \% \text { lamp to lamp }\end{array}$ \\
\hline
\end{tabular}

Table 1. Requirements for the main discharge pulse

\begin{tabular}{|l|l|}
\hline $\begin{array}{c}\text { Pre-ionization Pulse } \\
\text { Characteristics }\end{array}$ & \multicolumn{1}{|c|}{ Requirement } \\
\hline Discharge Pulse Shape & $\begin{array}{l}\text { Duration of power } \\
\text { pulse delivered to } \\
\text { flashlamps shall be 100 } \\
\mu s \pm 10 \%\end{array}$ \\
\hline Repeatability & $\begin{array}{l}\text { Total delivered energy } \\
\text { repeatable to } \pm 5 \% \text { shot } \\
\text { to shot }\end{array}$ \\
\hline Resolution & $\begin{array}{l}\text { Delivered energy } \\
\text { settable to } \pm 25 \%\end{array}$ \\
\hline Uniformity & $\begin{array}{l}\text { Energy variation }< \pm \\
3 \% \text { lamp to lamp }\end{array}$ \\
\hline $\begin{array}{l}\text { Energy delivered to } \\
\text { lamp }\end{array}$ & $>500 \mathrm{~J}$ \\
\hline
\end{tabular}

Table 2. Requirements for the main discharge pulse.

\section{MODULE DESCRIPTION}

The design of the NIF power conditioning module represents an evolution of development and improvements that have occurred over many years and several generations of lasers ${ }^{456}$ This evolution has been driven primarily by the need to continually reduce the incremental cost of supplying energy to drive lasers as the size of laser systems increase The design of the power conditioning systems for flashlamp pumped lasers has evolved from small independent modules that store less than $100 \mathrm{~kJ}$ to the NIF power conditioning system that stores nearly 2 $\mathrm{MJ}$ in a single module The direction of the evolution has been to build modules that can handle larger amounts of energy with a smaller number of components

The potential for failures to cause significant damage increases as the amount of energy in a single module increases The present module size and configuration represents an aggressive balance between cost and risk Significant development has been pursued in order to develop components that are either robust against all know failure modes or that fail in a well controlled fashion and can be easily replaced The design and predicted performance of the module will be described in the following sections

\section{A Module Design}

The NIF power conditioning module is designed to deliver a minimum of $34 \mathrm{~kJ}$ per flashlamp with easy expandability to approximately $40 \mathrm{~kJ}$ per flashlamp These two operating scenarios correspond to a total stored energy per module of $16 \mathrm{MJ}$ and $19 \mathrm{MJ}$ respectively A simplified schematic of a module is shown in Figure 4

Each module contains a maximum of 24 self-healing capacitors connected in parallel A resistive inductor, referred to as a damping element, is connected in series with each capacitor as shown in Figure 4 The purpose of this damping element is to limit fault currents in the event that one of the capacitors short internally or the output bus of the module gets shorted

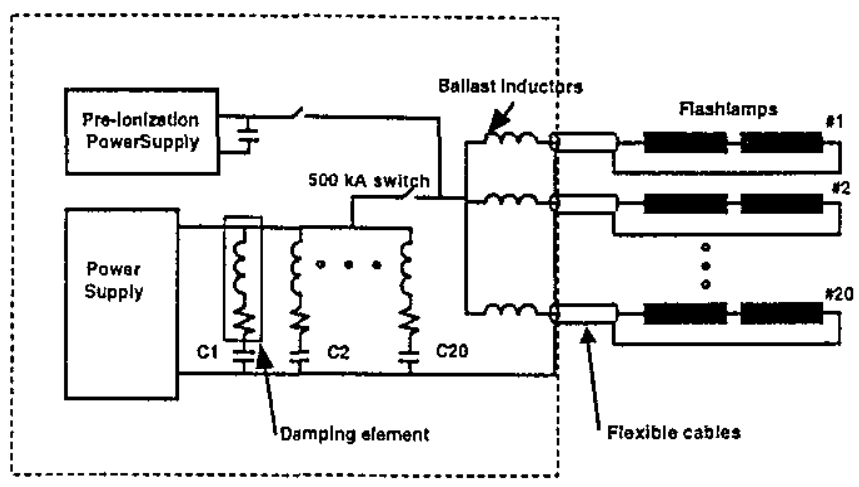

Figure 4. Schematic of power module. 
Each module is charged with its own capacitor charging power supply in approximately 60 seconds The 60 second charge time was chosen because it was an acceptable compromise between capacitor lifetime, switch prefire probability and power supply/prime power cost The voltage will be held at the requested charge voltage for a maximum of 15 seconds while other systems in NIF are synchronized and armed for the shot

The stored energy is discharged through a high power spark gap into a distribution network of 20 ballast inductors and transmission lines The purpose of the ballast inductors is to ensure that energy is delivered equally to all 20 flashlamps pairs Each flashlamp circuit will deliver nominally $68 \mathrm{~kJ}$ of energy to each flashlamp pair during the main discharge pulse

\section{B Fault tolerance}

The mechanical design of the module and its components is very important because of the total energy stored in the module of $16-19$ MJ Under notmal operation, peak currents of $550 \mathrm{kA}$ can exert significant forces on adjacent conductors and connectors It is important to insure that all components can easily withstand these forces during the 20,000 shot lifetime of the NIF To ensure module lifetime, all components are being designed and tested to withstand the mechanical forces of normal operation for 20,000 shots ${ }^{7}$

As the total stored energy in a single module is increased, the potential for significant damage resulting from a failure becomes much greater Under fault conditions, the mechanical design of the system must either withstand the forces or limit damage so that repairs can be completed in the time period between shots which is nominally $4-8$ hours In many cases, the philosophy adopted has been to limit damage because of the cost associated with building components that are robust against the most severe faults

Five significant faults have been identified for the NIF power conditioning module These faults are listed and described in Table 3

The module, shown in Figure 5, is completely enclosed in a $3 / 16$ inch steel This closed architecture was chosen because it facilitates the containment of both shrapnel and fire in the event of a major failure in the module
Damage would be limited to only the module that experienced the fault

\begin{tabular}{|l|l|}
\hline \multicolumn{1}{|c|}{ Fault } & \multicolumn{1}{c|}{ Description } \\
\hline Capacitor fault & $\begin{array}{l}\text { Internal short in } \\
\text { capacitor }\end{array}$ \\
\hline Bus fault & $\begin{array}{l}\text { Short between output } \\
\text { bus plates }\end{array}$ \\
\hline Feedthrough fault & $\begin{array}{l}\text { Short at module output } \\
\text { connector or in cable }\end{array}$ \\
\hline Termination fault & $\begin{array}{l}\text { Short in termination } \\
\text { block at load }\end{array}$ \\
\hline Flashlamp fault & $\begin{array}{l}\text { Discharge into faulty or } \\
\text { broken flashlamp }\end{array}$ \\
\hline
\end{tabular}

Table 3. Summary of potential power conditioning module faults

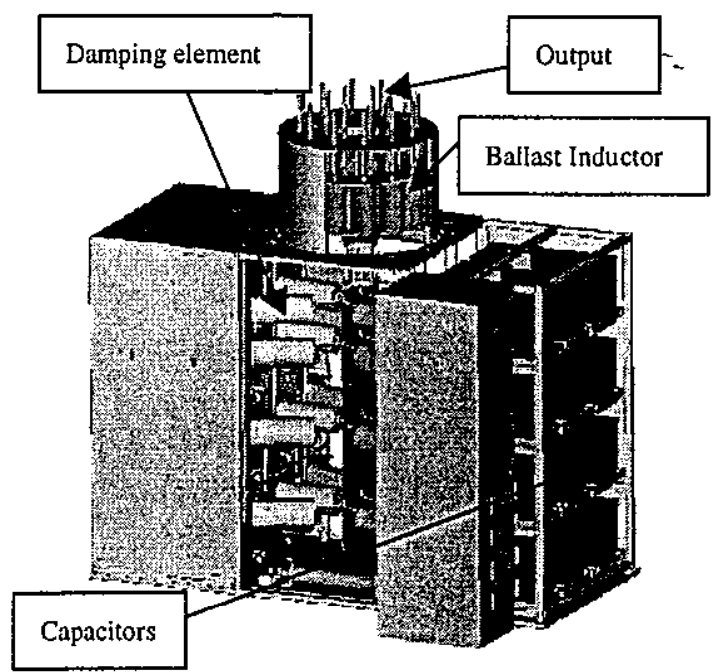

Figure 5. Power conditioning module with 24 capacitors.

The high cost items, such as capacitors, or items that would be difficult to replace, such as transmission lines, are being specified or designed to withstand the worst case fault For example, the worst case fault for capacitors is a bus fault where the peak discharge current from each capacitor can be almost four times its normal discharge current and the voltage reversal can be as high as $65 \%$ The capacitors are being designed to survive a limited number of these faults and still meet the overall lifetime requirement of 20,000 shots Cables are also being tested to insure that they can withstand the termination and flashlamp faults which is the worst fault for the cable 


\section{Predicted Module Performance}

The NIF power conditioning system has a total of 192 modules that must each meet the requirements specified in table 1 and table 2 There will be differences in individual module performances because of variations in the components For example, the delivered capacitance tolerance on the capacitors is $10 \%$

Sensitivity studies have been done to ensure that the NIF power conditioning system module design will meet all of the requirements with the expected tolerances on the module components The modeling was done by calculating the output power pulses of the module for a matrix of component values and using GainCalc v1 0 to calculate the gain coefficient that would result from that drive pulse The graph in Figure 6 shows the calculated gain coefficient for the different possible combinations of component values This graph shows that for expected variations in module output due to component variations, slight adjustments in the charge voltage, $11 \mathrm{kV}$ maximum, will easily compensate for differences in performance All modules meet the $50 \% / \mathrm{cm}$ requirement at 275 microseconds

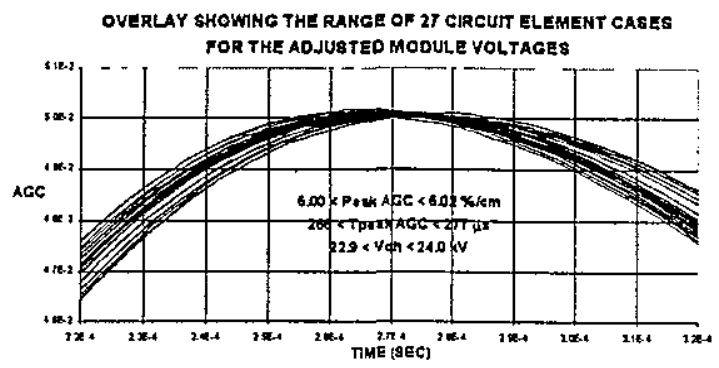

Figure 6. Calculation of gain coefficient for expected outputs from the modules.

\section{SUMMARY}

The design of the power conditioning system for the NIF laser system is nearing completion Modeling predicts that the design will meet all of the performance requirements The design will be validated through thorough testing before construction of the power conditioning system for NIF

\section{ACKNOWLEDGEMENTS}

This paper describes the work and contributions of many people, too numerous to list as coauthors Below is a list of the people who have made contributions to the designs described in this paper or have provided information

Sandia National Laboratory-David Smith, Chuck Harjes, Dennis Muirhead

Dave Van DeValde

Lawrence Livermore National Laboratory-Steve Fulkerson, Bill Gagnon

American Controls Engineering-Bob Anderson Maxwell/Physics International - Jud Hammon

Work performed under the auspices of the U S Department of Energy by Lawrence Livermore National Laboratory under Contract no W-7405Eng-48 and by Sandia National Laboratory under Contract no DE-AC04-94AL85000

\section{REFERENCES}

${ }^{1}$ Laser Program Annual Report, Lawrence Livermore National Laboratory, UCRL-5002174, pl13-115

${ }^{2} \mathrm{H}$ T Powell, A C Erlandson, KS Jancaitis, J E Murray, "Flashlamp Pumping of Nd Glass Disk Amplifiers", High-Power Solid State Lasers and Applications, , Vol 1277 The Hague, The Netherlands, SPIE, p103-120 (1990)

${ }^{3}$ GainCalc v1 0 , written by Ken Jancaitis, Lawrence Livermore National Laboratory

${ }^{4} \mathrm{~K}$ Whitham, D. Larson, B Merritt, D Christie, "NOVA Pulse Power Design and Operational Experience", Pulsed Power for Lasers, Proceedings of SPIE, T R Burkes, Volume 735, pp 12-17, Los Angeles, CA (1987)

${ }^{5} \mathrm{D}$ Larson, $\mathrm{R}$ Anderson, J Boyes, "Fault

Tolerance of the NIF Power Conditioning System", Proceedings of the First Annual Conference on Solid State lasers for Application to Inertial Confinement Fusion, $\mathrm{M}$ Andre, $\mathrm{H} \mathrm{T}$ Powell, Vol 2633, pp 587-595, SPIE, Bellingham, WA (1995)

${ }^{6} \mathrm{~W}$ L Gagnon, "The Near and Long Term Pulse Power Requirement for Laser Driven Inertial Confinement Fusion", Proceedings of the Second IEEE International Pulsed Power Conference, A H Guenther, M Kristiansen, pp 49-54, IEEE, Lubbock, TX (1979)

${ }^{7} \mathrm{M}$ A Newton, D W Larson, JM Wilson, HC Harjes, M E Savage, R L Anderson, "Power Conditioning Development for the National Ignition Facility", Solid State Lasers for Inertial Confinement Fusion, M.L Andre, vol 3047 part 2, pp 665-671, SPIE (1996) 


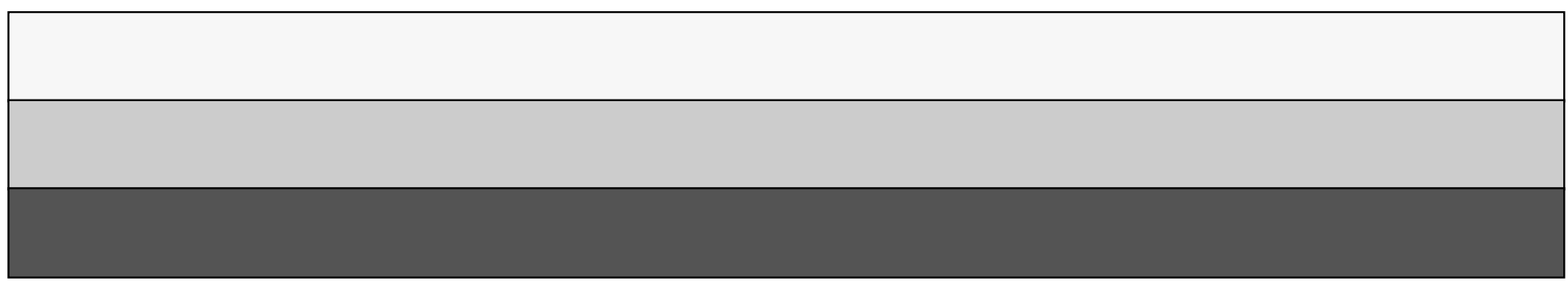

